\title{
IDOSO INSTITUCIONALIZADO: SENTIMENTOS DOS FAMILIARES EM RELAÇÃO A INSTITUCIONALIZAÇÃO
}

\author{
Institutionalized elderly: feelings of relatives regarding the institutionalization
}

\author{
Cristina Braga ${ }^{1}$, Márcia K. Koike ${ }^{2}$, Karen R. Saad ${ }^{3}$, Fernanda Pitanga ${ }^{4}$
}

${ }^{1}$ Doutoranda em Ciências da Saúde - IAMSPE - Área Envelhecimento Humano. ${ }^{2}$ Professora Doutora - IAMSPE - USP, SP. ${ }^{3}$ Professora Doutora - Universidade Federal do Vale do São Francisco, PE. ${ }^{4}$ Professora Mestre - Universidade Nove de Julho, SP.

\section{Resumo}

No contato frequente com as famílias das idosas institucionalizadas percebe-se a preocupação que as mesmas demonstram com relação à institucionalização da pessoa idosa. Acredita-se que o despreparo das famílias em cuidar do idoso em situação de vulnerabilidade seja o fator determinante para a institucionalização dos mesmos em ILPIs - Instituições de longa permanência para idosos. Este estudo objetivou descrever os sentimentos do familiar em relação à institucionalização do idoso em ILPI. Trata-se de um estudo de natureza quali-quantitativa, descritiva e exploratória retrospectiva transversal. A pesquisa foi realizada em uma Instituição de Longa Permanência para pessoas. A amostra foi constituída de 20 pessoas, familiares das internas de ambos os sexos, com mais de 18 anos que tinham a responsabilidade sobre a idosa institucionalizada e aceitaram participar do estudo mediante o termo de consentimento livre e esclarecido. O estudo foi aprovado pelo CEP da Universidade Nove de Julho, SP. Por meio desta pesquisa pôde-se constatar os familiares consideram a ILPI como local propiciador de acolhimento e tratamento ao idoso em situação de vulnerabilidade. No estudo foi também relatado sentimento de culpa, medo, impotência, sensação de abandono, saudades e outros. Concluiu-se que a percepção dos familiares, que fizeram parte da amostra sobre os motivos que os levaram à procura do asilamento de seus idosos está relacionada a acreditar que a Instituição asilar representa um local acolhedor e de bem-estar para seu ente querido, por estarem incapacitados de cuidar de seu familiar, não entendendo como abandono.

Palavras-chave: Idoso, Sentimentos Institucionalização, Asilamento.

\begin{abstract}
In Brazil, the elderly population is currently about $10 \%$ of the total population. Results of the census of 2010 reported that there was an increase in the elderly population aged 60 or more, up from $4.8 \%$ in 1991 , rising to $5.9 \%$ in 2000 , reaching $7.4 \%$ in 2010 . It is believed that the unpreparedness of families in caring for the elderly in vulnerable situations is the determining factor for the institutionalization of the same in ILPS therefore this study aimed to describe the feelings of the family regarding the institutionalization of the elderly in ILPI. It is a study of quantitative and qualitative, descriptive and exploratory retrospective cross. The survey was conducted on a long-stay institution for elderly dominated the female population with 80 older, with $90 \%$ of them are suffering from Alzheimer's disease. The sample consisted of 20 people, relatives of the internal of both sexes, older than 18 who had responsibility for the
\end{abstract}


institutionalized elderly and agreed to participate through the free and informed consent. It was concluded that the perception of family members, who were part of the sample about the reasons that led them to seek the isolation of their elderly, is related to believing that the Institution asylum represents a welcoming place and well-being for their loved one, for being unable to care for their family member, not understanding as abandonment.

Keywords: Elderly, Feelings Institutionalization, Asylum.

\section{Introdução}

A população com 60 anos de idade ou superior no País, vem aumentando e corresponde a 8,6\% da população total (cerca de 14 milhões). Para os próximos 25 anos estima-se que esta estatística poderá atingir mais de 30 milhões (BRASIL,2018; JÚNIOR, 2016).

Este aumento e a mudança do perfil social tornam-se importante considerando que nesta fase a pessoa idosa exige maior atenção e cuidados especiais. Tais cuidados deveriam ser confiados à família sendo este o ambiente propício onde todo o ser humano nasce, cresce e assimila valores tanto espirituais como morais e éticos que levará para sua vida adulta (BARROS, 2016; MELO, 2017).

Cuidar de um idoso no ambiente familiar não é tarefa muito fácil, especialmente se este se encontra com incapacidades funcionais (físicas e cognitivas), e quando esse é um membro da família, torna-se mais complicado, pois envolve sentimentos entre os idosos e seus familiares. Mas nas condições necessárias de cuidado, o afeto, a ajuda mútua e a compreensão são aspectos fundamentais no relacionamento entre o idoso e sua família. Por outro lado, nem todos os idosos podem dispor do cuidado de um familiar, considerando que muitos deles não têm familiares com laços de parentesco em primeiro ou segundo grau (CONFORTIN, 2019; SANTOS, 2013).

Mesmo que a legislação política pública acredite que o cuidado ao idoso deve ser prestado no ambiente familiar, entretanto caso o cuidado prestado pela família ao idoso se apresente pouco eficaz devido a situações diversas, pode surgir a necessidade de institucionalizado (COUTO, 2016)

As instituições de longa permanência para idosos (ILPI) são instituições governamentais ou não governamentais, destinadas a pessoas com idade igual ou superior a 60 anos de idade, em condição de liberdade, dignidade e cidadania. As Instituições devem estar de acordo com o regulamento técnico para o seu funcionamento garantindo o exercício de todos os direitos humanos de seus residentes (MICHEL, 2010)

Por isso, levando em consideração o suposto, bom funcionamento do ambiente institucional a família procura uma Instituição como local para seu familiar idoso e espera encontrar aí, entre outras demandas, um ambiente que ofereça cuidados, companhia, além de ser um espaço de convivência e socialização entre os institucionalizados (MICHEL, 2010; KANSO, 2017; SOUZA, 2017).

Embora as ILPIs dispensem aos idosos todos os cuidados necessários para o seu bemestar há o inconveniente que o idoso se afasta de seu convívio familiar, favorecendo o isolamento e a falta de atividade física e mental, com consequências negativas à sua qualidade de vida. Assim, a esfera multidisciplinar, dentro da Instituição deve proporcionar aos idosos residentes um cuidado ampliado. Por isso é importante que todos trabalhadores da ILPI, possam 
visualizar na família uma ferramenta indispensável na qualificação do cuidado ao idoso institucionalizado.

O enfermeiro precisa estar inserido na realidade da Instituição desempenhando com competência sua função contribuindo, assim, para a melhoria da qualidade de vida do idoso institucionalizado. Desta forma, entende-se que a família e o idoso, devem ser o foco de atenção da equipe multidisciplinar de trabalhadores de uma ILPI. Nesse sentido, a família poderia ser envolvida no planejamento e execução dos cuidados ao idoso institucionalizado (PETEGROSSO, 2018).

\section{Objetivo}

Descrever os sentimentos do familiar em relação ao asilamento de seu idoso em uma ILPI.

\section{Método}

Trata-se de um estudo de natureza quali-quantitativa, descritivo, exploratório retrospectivo transversal. A pesquisa foi realizada em uma Instituição de Longa Permanência para pessoas idosas onde predomina a população feminina com 80 idosas, sendo que $90 \%$ das mesmas são portadoras da Doença de Alzheimer. Esta ILPI teve sua origem em Roma, na Itália com fundação em 02 de fevereiro de 1892, com o objetivo de servir os doentes e idosos conforme o carisma transmitido por São Camilo de Lellis. Tal obra expandiu-se por diversas partes do mundo abrangendo quatro continentes: Europa, Ásia, África e América chegando ao Brasil em 1946, tornando-se presente em: São Paulo, Santa Catarina, Rio Grande do Sul, Paraná, Minas Gerais, Bahia e Mato Grosso. É uma empresa privada, sem fins lucrativos e tem como finalidade a assistência integral das idosas aí internas. A instituição ocupa 5 andares e as idosas residentes são classificadas, por cada andar, conforme o grau de dependência 19, sendo que nos andares TI e $1^{\circ}$ e $2^{\circ}$, há o predomínio das mais dependentes. (Grau de Dependência III), sendo identificado da seguinte forma: Andar TII (Térreo II): 11 idosas. G. D (Grau de dependência) I - 4; G.D II - 7; G.D III - 0; Andar TI: (Térreo I): 12 idosas. G. D (Grau de dependência) I - 0; G.D II - 6; G.D III - 6; Andar T: (Térreo): 15 idosas. G. D (Grau de dependência) I - 1; G.D II - 5; G.D III - 9; Andar 1º (Primeiro): 17 idosas. G. D (Grau de dependência) I - 0; G.D II - 1; G.D III - 16; Andar 2²: (Segundo): 25 idosas. G. D (Grau de dependência) I - 1; G.D II - 10; G.D III - 13.

A Instituição dispõe de pessoal qualificado como: médico, enfermeiras, auxiliares de enfermagem, Terapeutas ocupacionais, cuidadoras, fisioterapeutas, nutricionista, psicóloga e outros, no atendimento diário para com as idosas aí institucionalizadas. Para a aplicação da entrevista, foi necessário um ambiente livre de ruídos, sem a interferência de outrem, previamente combinado com os entrevistados. Para isso, utilizou-se um espaço reservado nos períodos fora de atendimentos, para não comprometer os resultados da pesquisa, bem como para garantir o sigilo com relação às pessoas estimou-se o tempo de 40 minutos para cada entrevistado. Essa condição é importante para cumprir os requisitos dos princípios éticos.

A amostra foi constituída de 20 pessoas, familiares das internas de ambos os sexos, com mais de 18 anos que tinham a responsabilidade sobre a idosa institucionalizada e aceitaram participar do estudo mediante o termo de consentimento livre e esclarecido. 
Pessoas da família ou parentes próximos maiores de 18 anos de ambos os sexos, responsáveis sobre a institucionalização da idosa. Pessoas que não fazem parte da família ou que não possuam grau de parentesco, com idade inferior a 18 anos, que não tinham responsabilidade sobre a idosa institucionalizada ou que não aceitaram participar deste estudo.

O familiar responsável pela idosa institucionalizada recebeu um documento de consentimento livre e esclarecido, com a finalidade de esclarecer a intenção da pesquisa, fazendo uma leitura prévia para tomar conhecimento do mesmo mediante a presença do pesquisador que se disponibilizou a esclarecer qualquer dúvida a respeito do referido documento. Os dados foram coletados no período de 22 de setembro de 2016 à 10 de outubro de 2016.

Para a coleta de dados foram utilizados dados primários e secundários, como: aplicação de um questionário elaborado pelo pesquisador, composto de duas partes: a primeira, para caracterizar a população pesquisada referente a data de nascimento, idade, profissão e grau de escolaridade, que serão apresentadas através de dados estatísticos e a segunda contendo seis perguntas abertas com o objetivo de obter informações sobre os sentimentos manifestos pela família ao institucionalizar a idosa. As perguntas foram lançadas a esta população, sendo respondidas de forma individualizada por tempo, de 40 minutos com cada participante. A aplicação do questionário foi efetuada pelo pesquisador, na tentativa de atender os objetivos desta pesquisa. As respostas de cada pessoa entrevistada serão gravadas e transcritas na íntegra. Após a transcrição, os conteúdos foram analisados de acordo com as respostas, aplicando o método de análise de conteúdo. Foram analisados de acordo com as respostas, aplicando o método de análise de conteúdo que é definido como uma técnica de investigação que através de uma descrição objetiva sistemática, qualitativa ou quantitativa que ajuda a descrever e a interpretar o conteúdo das mensagens e a atingir uma compreensão de seus significados num nível que vai além de uma leitura comum.

Os entrevistados foram identificados por grau de parentescos e idade e receberam nomes de flores como forma a preservar o sigilo e anonimato. Com a finalidade de deixar a amostra ciente dos propósitos e da metodologia da pesquisa, os mesmos foram explicados bem como os objetivos almejados com a referida temática para cada um dos participantes de acordo com seu interesse e tiveram autonomia de escolher participar ou não da pesquisa, isto é, foram selecionados de maneira não intencional.

Os participantes do estudo foram vinte familiares de residentes da Instituição de Longa Permanência. Em atenção à resolução 466/12 do Conselho Nacional de Saúde, que legisla sobre diretrizes e normas regulamentadoras de pesquisas envolvendo seres humanos, as participantes que concordaram fazer parte da pesquisa assinaram um termo de consentimento denominado Termo de Consentimento Livre e Esclarecido. Nesse termo, ficou assegurado o sigilo de sua identidade. Solicitou-se autorização para a realização do estudo à Instituição de Longa Permanência a fim de se obter permissão para dar início a pesquisa na referida instituição. A coleta dos dados se deu através de um questionário semiestruturado com perguntas fechadas e abertas, com o propósito inicial de identificar a amostra e posteriormente descrever o fenômeno em estudo. Os dados coletados foram organizados em tabelas e gráficos seguindo os parâmetros da análise descritiva com a aplicação da estatística descritiva que se limitou a descrever os dados observados. Nessa etapa, buscou-se estabelecer uma compreensão dos dados coletados, 
confirmando ou não os pressupostos da pesquisa e/ou responder à questão formuladas, bem como ampliar o conhecimento sobre o assunto.

Os dados foram organizados, analisados, apresentados em gráficos e submetidos à discussão qualitativa alguns fragmentos dos discursos foram selecionados e transcritos no texto como forma de elucidação das respostas abertas com base no referencial teórico encontrado na literatura.

\section{Resultados}

Após a leitura do material transcrito na coleta de dados foi feito uma análise quantitativa da amostra a fim de identificar o perfil dos entrevistados que segue abaixo:

A idade dos entrevistados variou entre 30 a 90 anos sendo que a maioria dos entrevistados se esquadram na faixa etária dos 60 a 69 anos 10 (50\%) dos entrevistados, 2 indivíduos (10\%) na faixa etária dos 70 aos 90 anos e 8 indivíduos (40\%) com idade entre 30 a 59 anos. Pode se observar que houve uma predominância de entrevistados com idade mais avançada neste estudo. Em relação ao gênero dos entrevistados a maioria foi feminino $13(65 \%)$ e 7 (35\%) do gênero masculino, quanto a escolaridade a grande maioria $12(60 \%)$ relatou ter nível superior completo, $6(30 \%)$ ensino médio completo e apenas $2(10 \%)$ ensino fundamental completo.

Estes dados podem justificar o asilamento destes idosos uma vez que o idoso estando fragilizado também se torna difícil ser cuidado por seu familiar, principalmente se o mesmo for portador de patologias crônicas incapacitantes.

Em determinadas situações ou períodos, a capacidade da família para o cuidado pode estar comprometida ou fragilizada e, nestas condições, o idoso pode constituir-se em um bloqueio à autonomia dos familiares, seja pelas demandas do cotidiano, que não lhes possibilita conciliar cuidado e atividades de trabalho e do lar, ou pela impossibilidade de dentre os familiares encontrar um ou mais membros que se disponibilizem e se responsabilizem pelo cuidado do idoso. A institucionalização, então, é uma das soluções encontradas para o problema (GIRANDON, LEITE, FURIN, 2007).

Em segundo momento foi realizado uma leitura das questões abertas norteadoras onde buscam-se dar espaço às evocações dos entrevistados. Esta atitude levou a realização de uma análise temática que possibilitou o acompanhamento dos relatos feitos pelos sujeitos da pesquisa com a temática abordada que se segue abaixo.

\section{- Quais os motivos que o (a) levaram a institucionalizar seu familiar?}

Sendo as narrativas advindas das vivencias pessoais de cada sujeito ouvido, observouse que eles consideram a ILP como local propiciador de acolhimento e tratamento a este idoso onde se pode estabelecer vínculos. Pois, as respostas obtidas são variadas, mas os motivos que mais interferem na institucionalização de sua idosa são a impossibilidade de o familiar cuidar devido o número reduzido de seus membros, sendo que em geral o cuidador já tem uma idade mais elevada e às vezes apresentando problemas de saúde que o impossibilitam a tal tarefa, e pela idosa necessitar de cuidados especiais, uma vez que a mesma não teria condições de realizar o autocuidado em diversos, ou mesmo em todos os aspectos. Também pela resistência 
da idosa em aceitar cuidados por parte de pessoas que não são da família, na própria residência. Pode-se constatar isto através das falas das pessoas a seguir:

"Em síntese, a impossibilidade de ter em casa, uma estrutura com recursos profissionais e técnicos, que melhor atendessem as necessidades e o bem-estar da minha mãe" (Papoula).

"Pelo grau de sua da doença e por não confiar nas pessoas que cuidavam de minha mãe, pois eu não tinha como estar todo tempo acompanhando" (Antúrio).

"A impossibilidade de mantê-la na própria casa pela idade avançada, doenças e também porque apesar de insistir em morar sozinha, ela deixou de ter condições de cuidar de si mesma. Ela não aceitava ninguém morando em sua casa e também não admitia morar com o filho. Após dois sérios incidentes (quebrado braço e internação em UTI) em dois anos consecutivos, acabou por aceitar que seria melhor ficar numa instituição desde que fosse um lugar sério, seguro, onde fosse realmente cuidada com o respeito e carinho que merece" (Gerânio).

Em meio a um contexto socioeconômico desfavorável, com as projeções demográficas apontando a explosão da população idosa no terceiro milênio, em face das possibilidades do aumento do tempo de vida e das adversidades sociais, envelhecer exige uma tomada de consciência de que este processo é uma realidade cada vez mais próxima de todos. Neste contexto histórico, no Brasil, a velhice sem autonomia, ainda faz parte de uma face oculta da opinião pública e vem sendo mantida no ambiente familiar dos domicílios e em instituições asilares, o que impede melhorar a visibilidade e a preocupação política de proteção social. Em geral, famílias brasileiras optam por institucionalizar seu idoso, quando a capacidade de lhes oferecer os cuidados necessários se esgota (ARAÚJO, 2007; PEREIRA, 2001)

\section{- O que o levou a procurar esta Instituição para seu familiar?}

A maioria das pessoas responderam que procuraram a Instituição por referência de outras pessoas internadas nesta Instituição e que falaram muito bem da mesma. Outras já tiveram parentes institucionalizadas e tiveram boa impressão da Instituição.

A formação dos profissionais, além de sua qualificação continuada é um aspecto fundamental para que a Instituição possa oferecer a seus clientes um atendimento de qualidade (POLLO, 2008).

O ambiente em uma Instituição de Longa Permanência (ILP) é repleto de geração de significados que vai constituir um cenário rico em simbolismos de rotinas, de costumes, de crenças e rituais. Para compreendê-los torna-se necessário ouvir, observar e interpretar; isto é estudar as cenas culturais para descobrirmos as diferentes formas de manifestações culturais da situação social que, muitas vezes, penetram de modo imperceptível nas atividades cotidianas dos profissionais que trabalham com idoso. Para desenvolver o cuidado de forma harmoniosa e digna é necessário compreender o significado que as pessoas expressam para as diferentes experiências de saúde-doença e isto é, de suma importância para que se obtenha um bom resultado na realização do cuidado (SILVA, 2005) 
"Em primeiro lugar, o temor a Deus, a caridade, respeito e dignidade" (Antúrio).

"Excelente referências e formação especializada por profissionais, além do carinho humanitário disponibilizado". (Jasmim)

"Eu tinha uma vizinha que a mãe dela já estava aqui há muitos anos e ela me trouxe para fazer uma visita e fiquei muito encantada com o lugar com o atendimento com o carinho das pessoas enfim eu trouxe minha mãe para aqui com tranquilidade" (Cravina).

\section{- Quais sentimentos você manifestou ao institucionalizar a idosa?}

Apesar de muitos dos entrevistados terem encontrado na Instituição um local acolhedor e de bem-estar para sua idosa, alguns manifestam sentimentos negativos, como: sentimento de culpa, impotência, sensação de abandono, saudade, etc. Outras relatam não sentirem remorso nenhum porque são conscientes que estão proporcionando o melhor para sua familiar idosa. As que manifestaram sentimentos negativos relatam que os mesmos vão sendo amenizados com o passar do tempo e por irem adquirindo maior familiaridade e confiança nos membros da Instituição e pelos cuidados que a mesma dispensa através de profissionais especializadas na área.

O envolvimento sincero e uma relação de igual para igual permitiria a minimização de sentimentos negativos, especialmente para a família e o idoso. Por outro lado, a instituição tem a oportunidade de conhecer melhor o contexto e, consequentemente, promover uma acolhida e assistência que vão ao encontro das necessidades e expectativas da família (PERLINI, 2007)

Tanto os familiares, como os idosos apresentam questionamentos, receios e expectativas quanto à internação. Por isso é de grande importância que o idoso receba apoio e acompanhamento e, possivelmente, acompanhe o processo de sua institucionalização para uma melhor adaptação e aceitação (POLLO, 2008).

No Brasil, atualmente, não existem dados exatos sobre o número de idosos institucionalizados e a demanda por esse atendimento. Não há também, estatística de que a procura pela institucionalização irá diminuir e nem há sinais de que a demanda seja diminuída, principalmente se não forem disponibilizadas alternativas para atender aos idosos e às suas famílias (POLLO, 2008; CORDEIRO, 2015).

"Com franqueza digo que não senti culpa. Senti tranquilidade por confiar na instituição e porque eu não teria condições de cuidar dela pessoalmente, porque ainda tenho filhos que moram comigo, e trabalho fora. Única coisa que lamento é o fato dada mamãe não ter condições de interagir com os bisnetos. Esta é uma condição dela e independente da institucionalização" (Lírio).

"Muita tristeza, fiquei depressiva mesmo sabendo estar num lugar maravilhoso, bem cuidada é difícil a separação" (Tulipa). 
"Foi como tirar de mim uma obrigação da qual eu não tinha condições de dar conta e que me causava uma enorme crise de consciência pela minha incapacidade" (Girassol).

- O que você espera da instituição em que se encontra a idosa?

Nota-se que $100 \%$ dos entrevistados esperavam encontrar carinho, apoio, dedicação e competência por parte dos profissionais e na prática puderam constatar. E por isso são muito gratos e demonstram satisfação. Isto demonstra que, mesmo enfrentando diversos desafios sociais, econômicos e morais inerentes ao estilo de vida da época, a Instituição consegue manter um padrão de qualidade no atendimento às idosas aí Institucionalizadas.

A família é considerada como fonte do cuidado e quando esta opta pela institucionalização de um de seus membros neste caso, o idoso, a decisão, reveste-se de uma intenção que visa proporcionar melhores condições de vida, de cuidado e de conforto, com maior qualidade que aquelas que a família pode oferecer (PERLINI, 2007).

"Cuidado, atenção aos sintomas que ela possa manifestar e que haja orientação. Higiene, asseio, é impossível tratar a idosa sem ter carinho. Por isso acho também um item importante responsabilidade da equipe, etc.” (Dália).

"Que o lado bom da instituição continuasse tratando as idosas respeitando a capacidade de cada uma e paciência com a família próxima. Só tenho a agradecer. Obrigada." (Gérbera).

"O que eu esperava da Instituição quando internei minha mãe, é exatamente o que tem acontecido. Ser tratada com respeito, cuidado, atenção e principalmente carinho. Espero que isto continue assim." (Gerânio).

Quando a família não possui mais alternativas para prestar cuidados ao idoso, opta pela institucionalização. Essa decisão, muitas vezes, tem o objetivo de proporcionar condições mais qualificadas do que a família pode oferecer no momento (PERLINI, 2007; SANTOS, 2013).

- Os cuidados dispensados pela instituição à sua parente idosa atingem as suas expectativas? Por quê?

As respostas obtidas relacionadas a esta questão, em sua maioria foram positivas. As pessoas demonstraram satisfação com o desempenho da Instituição, porém, uma minoria, isto é, uma pessoa respondeu que ainda não está satisfeita porque sua mãe não recebe a atenção que é dispensada para as outras idosas mais dependentes.

Sabe-se que em qualquer empresa não existe perfeição, sempre há pontos que necessitam ser aprimorados ou melhorados. Mas, pelo fato de ser uma pessoa entre as vinte pesquisadas, isto denota, neste caso, que a maneira negativa de ver as coisas pode estar relacionada a problemas de consciência por não ter condições de proporcionar à sua idosa o bem-estar que gostaria. Então o caminho mais lógico seria cobrar da Instituição aquilo que ela mesma não poderia oferecer. Neste caso, o papel dos profissionais da Instituição seria de 
escutar, compreender e ao mesmo tempo procurar desenvolver estratégias que tranquilizariam este familiar.

Diante da impossibilidade de manter a pessoa idosa no domicílio, a família começa a procurar pelo melhor local para que o idoso possa morar, ser bem atendido em suas necessidades e continuar mantendo vínculo com a família. Com o intuito de localizar tal espaço, são realizadas visitas a diferentes instituições, com a finalidade de identificar aquela que poderá melhor atender as suas expectativas. Na busca de um espaço, um fator que contribui na escolha do local relaciona-se à possibilidade de que o idoso possa organizar ali uma estrutura física o mais semelhante possível ao de sua casa (KANSO, 2016; PERLINI, 2007; BASTIANI, 2016)

"Sim. Porque a minha mãe vem sendo muito bem tratada, nesses quase cinco anos." (Papoula).

"Ainda não, pois sinto que a instituição prioriza cuidados maiores com os mais dependentes como minha mãe é mais independente sinto que não há tanta atenção." (Copo de Leite).

"Sim. Tudo que encontrei aqui: eficiência, carinho, atenção, recreação, alegria pontualidade religião supervisão constante, médicos atentos as necessidades e nos diagnósticos.” (Palma).

A atenção e o cuidado dispensados ao idoso nas instituições é uma tradição marcante. $\mathrm{Na}$ realidade do envelhecimento tal prerrogativa tenta preencher a lacuna aberta pela impossibilidade de a família atender as necessidades de seus idosos e encontrar medidas e formas de intervenção que permita proporcionar uma prestação de cuidados que leve em consideração a sua individualidade e necessidade (LENRDT, 2006).

\section{- Como é o seu relacionamento com os membros da Instituição?}

A comunicação é um processo fundamental na vida dos seres humanos. A forma de comunicar-se é muito importante pois interfere no bom ou mau relacionamento entre os seres humanos. Analisando desta forma, nota-se que, todos responderam que mantêm um ótimo relacionamento na Instituição, pois, quando o familiar procura dialogar com algum membro da Instituição, este deve ser ouvido com atenção e respeito, pois já estão fragilizados e se encontram apoio e compreensão, ficam mais tranquilos e envolvidos nos processos de cuidados dispensados a sua familiar idosa. Desta forma, o bom relacionamento entre o familiar e os membros da Instituição, sem dúvida vai interferir e estimular o desenvolvimento de uma maior confiança nos serviços prestados pela instituição.

Considerar a importância da convivência pode ser uma forma de motivação para desenvolver atitudes que mantenham o equilíbrio afetivo entre o idoso e sua família e o papel da Enfermagem neste processo é de suma importância. Pois, inteirar-se dos problemas inerentes a esta fase que se encontra o ser humano é fundamental para buscar e elaborar estratégias que favoreçam um relacionamento mais saudável entre o idoso e seu familiar (PERLINI, 2007; SIMÕES,2016; FERNANDES, 2017). 
Para Michel (2010), o cultivo de relacionamentos entre idosos e familiares são muito significativos sendo considerada uma necessidade básica da sobrevivência humana e atribui se à ILPI o papel de manter os vínculos familiares e a integração das pessoas idosas residentes na Instituição.

Os profissionais das instituições para idosos, devem ajudar as famílias e os idosos a lidarem melhor com a questão do relacionamento que às vezes não são tão favoráveis para uma melhor qualidade de vida. Por isso, torna-se necessário cuidar dessas três dimensões (CREUTZBERG, 2007; SILVA, 2012; FECHINE, 2015; CHOU, 2016).

"Muito bom tenho um ótimo relacionamento c/ todos os profissionais". (Begônia)

"MUITO BOM. Sempre que foi necessário conversar, trocar ideias, solicitar informações houve espaço para tanto. A instituição por meio de seus funcionários (cuidadores atendentes em geral da área da saúde sempre entram em contato quando necessário e a forma de relacionamento atencioso". (Lisianto).

"Meu relacionamento é excelente. Aliás não poderia deixar de sê-lo, uma vez que, além do extremo profissionalismo, são todos extremamente cordiais, atenciosos e dedicados, deixando os familiares totalmente à vontade e se esforçando ao extremo para atender prontamente e de forma positiva nessas necessidades. Sinto-me acolhido por todos”. (Gerânio)

Há necessidades psicológicas e afetivas que só podem ser mediadas de forma mais positiva caso haja diálogos entre idosos e familiares. Ser idoso é ter um corpo condicionado em termos orgânicos, sociais e psicológicos muitas vezes dependentes de outros, principalmente se houver a presença de agravos, que possam influenciar nas AVDs (Atividades da Vida Diárias) deste indivíduo.

\section{Considerações Finais}

Por meio desta pesquisa pôde-se constatar que, apesar das dificuldades e relutâncias que a família encontra para institucionalizar seu familiar, os mesmos consideram a ILP como local propiciador de acolhimento e tratamento a este idoso onde se podem estabelecer vínculos e confiar nos serviços prestados pela Instituição.

Com relação aos motivos que levaram o familiar institucionalizar sua familiar idosa, as respostas obtidas são variadas, mas os que mais interferem na institucionalização de sua idosa são a impossibilidade de o familiar cuidar devido o número reduzido de seus membros, sendo que em geral o cuidador já tem uma idade mais avançada e às vezes apresentando problemas de saúde que o impossibilitam a tal tarefa, e pela idosa necessitar de cuidados especiais, uma vez que a mesma não teria condições de realizar o autocuidado. Também pela resistência da idosa em aceitar cuidados por parte de estranhos na própria residência.

Ao questionar os familiares sobre os motivos que os levara à procura desta Instituição para a sua idosa, entre outras respostas, a maioria relatou que procurou a Instituição por referência de outras pessoas internadas na mesma Instituição e que falaram positivamente da 
mesma. Outras já tiveram parentes institucionalizadas e receberam boa impressão da Instituição.

Por tais argumentos percebe-se que, uma Instituição de Longa Permanência deixa de ser um paradigma no pensamento de muitas pessoas que a viam como um lugar que transmitia uma impressão negativa onde os idosos permaneceriam isolados, sem atividades e interação alguma, ou seja, como um depósito de seres humanos inválidos.

Apesar de muitos dos entrevistados terem encontrado na Instituição um local acolhedor e de bem-estar para sua idosa foi observado sentimento de culpa, medo, impotência, sensação de abandono, saudade e outros. Outras relatam não sentirem remorso algum porque são conscientes que estão proporcionando o melhor para seu familiar. As que manifestaram sentimentos negativos relatam que os mesmos vão sendo amenizados com o passar do tempo e por vão adquirindo maior familiaridade e confiança nos membros da Instituição e pelos cuidados que a mesma dispensa através de profissionais especializadas na área.

Em geral, os familiares esperam encontrar na Instituição, carinho, apoio, dedicação e competência por parte dos profissionais e na prática puderam constatar. E por isso são muito gratos e demonstram satisfação. Isto demonstra que, mesmo enfrentando diversos desafios sociais, econômicos e morais inerentes ao estilo de vida da época, a Instituição consegue manter um padrão de qualidade no atendimento às idosas institucionalizadas.

Sobre os cuidados dispensados pela Instituição a pesquisa mostra que as pessoas sentem atingir suas expectativas e demonstram satisfação com o desempenho da Instituição, porém um dos pesquisados respondeu que ainda não está satisfeito alegando que sua mãe não recebe a atenção que é dispensada para as outras idosas mais dependentes.

Neste contexto, sabe-se que em qualquer empresa não existe perfeição, sempre há pontos que necessitam ser melhorados. Mas, pelo fato de ser uma pessoa entre as vinte pesquisadas, isto denota, neste caso, que a maneira negativa de ver as coisas pode estar relacionada a problemas de consciência do familiar por não proporcionar à sua idosa o bemestar que gostaria. Isto demonstraria uma maneira de transferir para a Instituição a responsabilidade que deveria ter com relação ao seu idoso. Neste caso, o papel dos profissionais da Instituição seria de escutar, compreender e ao mesmo tempo procurar desenvolver estratégias que tranquilizariam este familiar.

A comunicação é um processo fundamental na vida dos seres humanos. A forma de comunicar-se é muito importante pois interfere no bom ou mau relacionamento entre os seres humanos. Analisando desta forma, sobre o relacionamento dos familiares com os membros da Instituição, nota-se que, todos mantêm um ótimo relacionamento, pois, quando o familiar procura dialogar com alguém da Instituição o mesmo deve ser ouvido com atenção e respeito, pois já estão fragilizados e se encontram apoio e compreensão, ficam mais tranquilos e envolvidos nos processos de cuidados dispensados a sua familiar idosa. Desta forma, o bom relacionamento entre o familiar e os membros da Instituição, sem dúvida vai interferir e estimular o desenvolvimento de uma maior confiança nos profissionais e na própria Instituição.

Deste estudo, conclui-se, então, que em geral, os familiares confiam no trabalho da Instituição e esperam que a mesma continue prestando serviços com competência, qualidade e respeito à sua idosa institucionalizada. Portanto, é necessário que fiquemos atentos com relação 
a tais questões, considerando que podemos achar que tudo está bem e nos acomodarmos em certas questões. Já que a afetividade ocupa um espaço especial em nossa vida e que cada pessoa é única, é necessário que o nosso atendimento não fique apenas no serviço com os institucionalizados, mas que este se estenda também aos seus familiares procurando meios de proporcionar-lhes um ambiente de acolhida e um atendimento individualizado para que o mesmo se sinta mais compreendido e valorizado em sua totalidade de ser humano, contribuindo desta forma, para que o familiar se envolva no atendimento ao seu familiar idoso proporcionando-lhes uma melhor qualidade de vida do próprio idoso. Para melhor compreensão da realidade pela qual passam familiares e idosos seria interessante dar prosseguimento a este estudo comparando os dados com outras instituições.

\section{Referências}

ARAÚJO, Maria Odete Pereira Hidaldo de et al. Avaliação do grau de independência de idosos residentes em instituições de longa permanência. Revista da Escola de Enfermagem da USP, 2007.

BASTIANI, Fabíola; DOS SANTOS, Idenéia Silveira. Sentimentos Despertados nos Idosos Internados em Casas Asialres. Disciplinarum Scientia| Saúde, v. 1, n. 1, p. 113-124, 2016.

BARROS, Temístocles Vicente Pereira et al. Capacidade funcional de idosos institucionalizados: revisão integrativa. ABCS Health Sciences, v. 41, n. 3, 2016.

BRASIL. http://www.brasil.gov.br. Acesso em 27 de outubro de 2018.

CONFORTIN, Susana Cararo et al. Anthropometric indicators associated with dementia in the elderly from Florianópolis-SC, Brazil: EpiFloripa Ageing Study. Ciência \& Saúde Coletiva, v. 24, n. 6, p. 2317-2324, 2019.

CORDEIRO, Lucélia Malaquias et al. Qualidade de vida do idoso fragilizado e institucionalizado. Acta Paulista de Enfermagem, v. 28, n. 4, p. 361-366, 2015.

COUTO, Alcimar Marcelo; DE CASTRO, Edna Aparecida Barbosa; CALDAS, Célia Pereira. Vivências de ser cuidador familiar de idosos dependentes no ambiente domiciliar. Revista da Rede de Enfermagem do Nordeste, v. 17, n. 1, p. 76-85, 2016.

CREUTZBERG, Marion et al. A comunicação entre a família e a Instituição de Longa Permanência para Idosos. Revista Brasileira de Geriatria e Gerontologia, v. 10, n. 2, p. 147160, 2007.

DA SILVA, Milena Valdinéia et al. O significado de ser idoso e conviver em uma instituição asilar. Revista de Pesquisa Cuidado é Fundamental Online, v. 5, n. 6, p. 325-337, 2013. 
DE MELO, Laércio Almeida et al. Fatores socioeconômicos, demográficos e regionais associados ao envelhecimento populacional. Revista Brasileira de Geriatria e Gerontologia, v. 20, n. 4, p. 494-502, 2017.

FERNANDES, Janaína da Silva Gonçalves; DA COSTA, Beethoven Hortencio Rodrigues; DE ANDRADE, Márcia Siqueira. Representações Sociais de Idosos sobre Família. Ciências Psicológicas, p. 41-48, 2017.

JÚNIOR, Cláudio Santiago Dias; COSTA, Carolina Souza. O envelhecimento da população brasileira: uma análise de conteúdo das páginas da REBEP. Anais, p. 1-21, 2016.

KANSO, Solange et al. As instituições de longa permanência para idosos no Brasil. Anais, p. $1-17,2016$.

LENARDT, Maria Helena et al. O idoso institucionalizado e a cultura de cuidados profissionais. Cogitare Enfermagem, v. 11, n. 2, p. 117-123, 2006.

MICHEL, Tatiane et al. Significado atribuido por los ancianos a la vivencia en una institución de larga permanencia: contribuciones a los cuidados de enfermería. Texto \& ContextoEnfermagem, v. 21, n. 3, p. 495-504, 2012.

PEREIRA, Maria Alice Ornellas; CAIS, Daiane Patricia. A percepção de familiares de pacientes psiquiátricos a respeito do serviço de saúde oferecido. Revista Gaúcha de Enfermagem, v. 22, n. 2, p. 90, 2001.

PERLINI, Nara Marilene O. Girardon; LEITE, Marinês Tambara; FURINI, Ana Carolina. Em busca de uma instituição para a pessoa idosa morar: motivos apontados por familiares. Revista da Escola de Enfermagem da USP, v. 41, n. 2, p. 229-236, 2007.

PETEGROSSO, Aline Franco; FERRARI, Flávia Paganini Costa. O trabalho social com idosos e suas famílias. Revista Longeviver, 2018.

POLLO, Sandra Helena Lima; DE ASSIS, Mônica. Instituições de longa permanência para idosos-ILPIS: desafios e alternativas no município do Rio de Janeiro. Revista Brasileira de Geriatria e Gerontologia, v. 11, n. 1, p. 29-43, 2008.

SIMÕES, Regina; DE MOURA, Marcia Marques; MOREIRA, Wagner Wey. Esperando a Morte: O corpo Idoso Institucionalizado. Polêm! ca, v. 16, n. 3, p. 049-061, 2016. 